\title{
Surveillance Implementation Group
}

National Cancer Institute

\section{Source}

National Cancer Institute. Surveillance Implementation Group. NCI Thesaurus. Code C19782.

A group with the purpose to identify what cancer surveillance research is most needed and how best to advance our knowledge of cancer based on the opportunities available. The SIG was charged with providing advice and recommendations for expanding and enhancing NCl's Cancer Surveillance Research Program. 